\title{
Effect of a Retarding Admixture on the Setting Time of Cement Pastes in Hot Weather
}

\author{
Bazid Khan $^{*}$ and Muhammad Ullah ${ }^{* *}$ \\ * Assistant Prof. B-Tech. Civil, Govt. College of Technology Peshawar- \\ PAKISTAN, ** Deputy Director Technical Education NWFP - PAKISTAN
}

\begin{abstract}
While concreting in hot weather, both setting time and compressive strength are adversely affected. To prevent concrete from the adverse effects of hot weather, admixtures are usually incorporated in it. The objective of this paper is to investigate the effects of a retarding admixture (ASTM C 494 Type D) on setting time of cement pastes. The setting time tests were performed under three different curing conditions (temperature \& relative humidity). The admixture was added to pastes made from three different types of cements. The test results revealed that the effects of admixture on setting time of cement pastes are dependent upon the type of cement and dosage of the admixture. It caused set retardation of the three different types of cements used, but with one type of cement it accelerated, the initial setting time and retarded the final setting time when dosages higher than $0.25 \%$ were used.
\end{abstract}

\section{Introduction}

When water is added to cement, paste is formed which gradually stiffens and then hardens. The stiffening of cement paste is called setting [1]. Basically, setting is a process of transformation from an initial state, a scattered concentrated suspension, to a final state, a connected and strengthened system of particles. This transformation in the practice of cement and concrete is obtained by chemical reactions between cement particles and water (i.e., cement hydration) [2]. Normal setting of cement is associated with the hydration of Alite (impure $\mathrm{C}_{3} \mathrm{~S}$ ) and formation of the calcium silicate hydrate $(\mathrm{CSH})$ phase [3]. 
Cement paste / concrete sets gradually under the standard laboratory conditions (temperature $\sim 23^{\circ} \mathrm{C}$ and relative humidity not less than $90 \%$ ) [4] but outside the laboratory concreting has to be done under the prevailing climatic conditions. In some countries including the author's country concrete is subjected to hot weather, which is defined as "any combination of high air temperature, low relative humidity, wind velocity and intensities of solar radiation tending to adversely affect the quality of fresh and hardened concrete [5].

Hot weather causes rapid evaporation of water from the surface of the fresh paste / concrete. Consequently the paste / concrete sets rapidly than its normal setting and shortens the length of time for concreting operations. For example, it has been reported that when the temperature of cement mortar with water/cement $(\mathrm{w} / \mathrm{c})$ ratio of 0.6 is increased from $27^{\circ} \mathrm{C}$ to $45.5^{\circ} \mathrm{C}$, both the initial and final setting times are halved [6]. Other problems such as rapid decrease of slump [7], formation of cold joints and plastic shrinkage cracking [8], increased difficulty in air entrainment [7], enhanced permeability and reduced durability [9] and reduction in ultimate strength [10] may arise due to hot weather.

Retarders are used in concrete to offset the accelerating effects of high temperatures which decrease setting times, or to avoid complications when unavoidable delays between mixing and placing occur [11].

Retarders are used in concrete to (i) offset the accelerating effects of hot weather on the setting times of concrete or (ii) delay the initial set of concrete / grout when difficulty or unusual conditions of placement occur such as placing concrete in large piers and foundations, cementing of oil wells and pumping of grout or concrete over considerable distances [8].

Retarding admixture is an admixture that retards the setting of concrete [12]. A retarding admixture causes cement set retardation by one or more of following mechanisms:

(1) Adsorption of the retarding compound on the surface of cement particles, forming a protective skin which slows down hydration;

(2) Adsorption of the retarding compound on to nuclei of calcium hydroxide, poisoning their growth, which is essential for continued hydration of cement after the end of induction period;

(3) Formation of complexes with calcium ions in solution, increasing their solubility and discouraging the formation of the nuclei of calcium hydroxide referred to in (2) above; and

(4) Precipitation around cement particles of insoluble derivatives of the retarding compounds formed by reaction with the highly alkaline aqueous solution, forming a protective skin [13]. 
According to the first mechanism, a retarding admixture is adsorbed on the surface of cement particles. This layer of retarding admixture around the cement particles acts as a diffusion barrier. Due to this diffusion barrier, it becomes difficult for the water molecules to reach the surface of the unhydrated cement grains and hence the hydration slows down, and the dormant period (period of relatively inactivity) is lengthened. Due to the slow hydration, no considerable amount of the hydration products giving rigidity to the cement paste will be formed and thus the paste remains plastic for a longer time. Later, when the admixture is removed from solution by reaction with $\mathrm{C}_{3} \mathrm{~A}$ from cement or by some other way it is removed and incorporated into the hydrated material, further hydration is eliminated.

On first contact of water with cement grains $\left(\mathrm{C}_{3} \mathrm{~S}\right.$ and $\left.\mathrm{C}_{2} \mathrm{~S}\right)$ calcium ions and hydroxyl ions are rapidly released from the surface of the cement grains. When concentration of these ions reaches a critical value (at which the solution becomes saturated), the hydration products calcium hydroxide and calcium silicate hydrate start to crystallize from the solution and then hydration proceeds rapidly. According to the second mechanism, a retarding admixture incorporated into cement paste is adsorbed on the calcium hydroxide nuclei and prevents its growth until some level of super saturation is reached during the induction period of hydration. Thus, retarder lengthens the induction period by causing an increase in the level of calcium hydroxide super saturation before crystallization begins. This is analogous to the poisoning of crystal growth of calcium hydroxide by the retarding admixture as both calcium and hydroxyl ions are present in the solution but unable to precipitate as a result of poisoning of the calcium hydroxide nuclei.

According to the third mechanism, a retarding admixture incorporated into cement paste forms some kind of complexes with calcium ions released by the cement grains during the first few minutes. Formation of the complexes increase the solubility of cement, i.e., increased concentration of $\mathrm{Ca}^{2+}, \mathrm{OH}, \mathrm{Si}$, $\mathrm{Al}$ and $\mathrm{Fe}$ in the aqueous phase of the cement pastes will occur when hydrated in the presence of the retarding admixture [14]. Thus the calcium ions and hydroxyl ions will accumulate in solution and will be unable to precipitate to form calcium hydroxide. For example, when ordinary Portland cement is hydrated in sucrose solution, lime is solubilised and a sucrose calcium complex $\left(\mathrm{R}-{ }^{-} \mathrm{O}-\mathrm{Ca}^{+}-{ }^{-} \mathrm{OH}\right)$ is formed in which $\mathrm{Ca}^{+}-{ }^{-} \mathrm{OH}$ group is attached to the five membered ring $(\mathrm{R})$ of the sucrose molecule. Such sucrose-calcium complex will be able to become absorbed on the growing calcium hydroxide nucleus. The adsorption of the complex on the calcium hydroxide nucleus will inhibit its growth as the calcium and hydroxyl ions will not be able to precipitate [14]. In this way, hydration is retarded. 
The fourth mechanism is similar to the first but here some kind of insoluble derivatives of retarder are formed by reaction with the highly alkaline solution as $\mathrm{pH}$ of the solution rises to over 12 within few minutes after first contact of water with cement. For example, inorganic salt admixtures (borates, phosphates, zinc and lead salts etc.) give insoluble hydroxides in alkaline solution. The cement hydration is suppressed through the precipitation of protective coatings of these insoluble derivatives around the cement grains [15]. The layer of these coatings acts as a diffusion barrier and makes it difficult for water molecules to

Retarding admixtures are mainly based on materials having lignosulfonic acids and their salts, hydroxy-carboxylic acids and their salts, sugar and their derivatives and inorganic salts such as borates, phosphates, zinc and lead salts [16].

Retarding effects of a retarder depends upon a number of factors including dosage of the admixture, time of addition to the mix and curing conditions. Some admixtures act as retarders when used in small amounts but behave as accelerators when used in large amounts. For example, sugar behaves as a set retarder but the large amount of sugar $(0.2$ to $1 \%$ by the weight of cement) will virtually prevent the setting of cement [7]. At higher temperatures some retarders become less effective in cement set retardation than at lower temperatures. For example, the efficiency of either hydrophobic material or super plasticizers in retarding cement setting is lower at higher temperatures $\left(35^{\circ} \mathrm{C}\right.$ and $\left.50^{\circ} \mathrm{C}\right)$ than at lower temperature $\left(20^{\circ} \mathrm{C}\right)[17]$.

A number of commercial products are available to be used as cement set retarders. The conventional retarding admixtures delay the setting time of concrete by few hours, while some of the advanced products such as Dalvocrete System ' keeps wet and dry shotcrete mixes fresh for any desired period of time, up to 3 days [18].

Because of retarding action, the one day strength of concrete is reduced. However, ultimate strength is reported to be improved by using set controlling admixtures. Rate of drying shrinkage and creep would increase by using retarders, but the ultimate values cannot increase [11].

\subsection{Materials}

\section{Experimental Work}

Cements: Three different types of cements were used for setting time tests. These are denoted as type-A, type-B, and type-C. Their oxide and compound composition and some other properties provided by the manufacturers are given 
in Table 1. Type-A and type-B cements are pozzolanic type cements, which approximately correspond to the ASTM type IP. Type-A cement is obtained by adding $6-20 \%$ calcined clay to the normal Portland cement clinker during manufacturing while in type-B cement the calcined clay ranges from 21 to $35 \%$. Their compound composition cannot be calculated by using Bogue's or other such formula. The type-C cement corresponds to the ASTM C 150 type-III cement. Its compound composition found by Bogue's formula is given in the Table 1 .

Table 1: Oxide and Compound Composition of Cements.

\begin{tabular}{|c|c|c|c|c|}
\hline Name & Abbreviation & Type-A & Type-B & Type-C \\
\hline Silica & $\mathrm{SiO} 2$ & 23.79 & 33.06 & 19.30 \\
\hline Alumina & $\mathrm{A} 12 \mathrm{O} 3$ & 6.33 & 7.43 & 5.38 \\
\hline Ferric oxide & $\mathrm{Fe} 2 \mathrm{O} 3$ & 3.52 & 3.33 & 2.89 \\
\hline Lime & $\mathrm{CaO}$ & 57.20 & 45.03 & 62.78 \\
\hline Magnesia & $\mathrm{MgO}$ & 0.69 & 0.90 & 1.66 \\
\hline Sodium & $\mathrm{Na} 2 \mathrm{O}$ & - & 0.10 & 0.55 \\
\hline Potassium & $\mathrm{K} 2 \mathrm{O}$ & 1.03 & 1.46 & 0.75 \\
\hline Sulfur trioxide & $\mathrm{SO} 3$ & 2.00 & 2.07 & 3.17 \\
\hline Chloride & $\mathrm{Cl}-$ & 0.019 & 0.0266 & 0.0089 \\
\hline Loss on ignition & L.O.I. & 2.14 & 4.21 & 3.29 \\
\hline Undetermined & - & 3.28 & - & - \\
\hline$\%$ Free Lime & $\% \mathrm{~F} . \mathrm{CaO}$ & 1.37 & 0.39 & 0.77 \\
\hline Insoluble Residue & I.R. & - & 29.06 & 0.42 \\
\hline Soundness (mm) & - & 2.00 & 3 & 1.00 \\
\hline Specific gravity & - & 3.03 & - & 3.08 \\
\hline $\begin{array}{l}\text { Weight per liter } \\
(\mathrm{g} / \mathrm{lt})\end{array}$ & - & 984 & 910 & 1050 \\
\hline $\begin{array}{l}\text { Fineness-specific } \\
\text { surface }(\mathrm{cm} 2 / \mathrm{g})\end{array}$ & - & 3661 & 4963 & 3759 \\
\hline $\begin{array}{l}\text { Lime Saturation } \\
\text { Factor }\end{array}$ & L.S.F. & -71.6 & 42.00 & 99.15 \\
\hline $\begin{array}{l}\text { Hydraulic } \\
\text { Modulus }\end{array}$ & H.M. & -1.7 & 3.05 & 2.31 \\
\hline Silica Modulus & S.M. & -2.42 & 0.37 & 2.29 \\
\hline Alumina Modulus & A.M. & -1.80 & 2.23 & 1.86 \\
\hline $\begin{array}{l}\text { Tricalcium } \\
\text { Silicate }\end{array}$ & $\mathrm{C} 3 \mathrm{~S}$ & - & - & 59.51 \\
\hline Dicalcium Silicate & $\mathrm{C} 2 \mathrm{~S}$ & - & - & 10.76 \\
\hline $\begin{array}{l}\text { Tricalcium } \\
\text { Aluminate }\end{array}$ & $\mathrm{C} 3 \mathrm{~A}$ & - & - & 9.37 \\
\hline $\begin{array}{l}\text { Tetracalcium } \\
\text { Aluminoferrite }\end{array}$ & $\mathrm{C} 4 \mathrm{AF}$ & - & - & 8.79 \\
\hline
\end{tabular}

These three types of cement were selected for the research purpose because the cement factories in that region do not manufacture normal Portland cement. Secondly, their manufacturers for using in those conditions where the use of 
normal Portland cement is not beneficial, recommended the type-A and B cements.

Mixing Water and Retarding Admixture: Normal tap water was used as mixing water. The retarding admixture used was ASTM C 494 type D admixture. Its density was about $1.02 \mathrm{mg} / \mathrm{ml}$ and its chloride content was claimed nil. The amount of the admixture incorporated into the pastes was expressed in $\mathrm{ml} / 100 \mathrm{~g}$ of cement indicated as percentage.

Mixes: Cement pastes were prepared for determination of consistency and setting times tests. The cement content and w/c ratios were kept constant for all tests for a given cement type. The amounts of cement and water used per test are shown in Table2.

Table 2: Amounts of Cement and Water Used per Test.

\begin{tabular}{|c|c|c|c|}
\hline Type of cement & Amount of cement $(\mathrm{g})$ & Water $(\mathrm{ml})$ & W/c ratio (\%) \\
\hline Type-A & 400 & 130 & 32.50 \\
\hline Type-B & 385 & 130 & 33.75 \\
\hline Type-c & 400 & 110 & 27.50 \\
\hline
\end{tabular}

Equipment: A Vicat apparatus was used for determination of both the standard consistency and setting times of pastes. The apparatus was similar to that recommended by the ASTM C 187-77 and C 191-77 except the minor difference in the needle and ring (mold) dimensions. The needle of the apparatus was $1.13 \mathrm{~mm}$ in diameter and $46 \mathrm{~mm}$ long. The ring had an inside diameter of $90 \mathrm{~mm}$ at the base and $80 \mathrm{~mm}$ at its top.

\subsection{Determination of standard consistency and setting times:}

For standard consistency determination, the procedure of the ASTM C 18777 was followed and for setting time determination, the Turkish Standard 19 (TS-19) was followed. The TS-19 nearly follows the ASTM C 191-52 procedure with minor amendments as described below:

The initial set is said to have taken place when the needle $(1.13 \mathrm{~mm}$ dia.) of theVicat apparatus ceases to pass 3-5 $\mathrm{mm}$ above the bottom of cement paste taken in the Vicat mould. Final set is said to have occurred when the needle penetrates the cement paste to a maximum depth of $1 \mathrm{~mm}$. In both cases, the setting time is reckoned from the moment when mixing water is added to the cement.

\subsection{Curing Conditions}

In order to simulate the approximate normal and adverse outdoors climatic conditions, the following three categories of curing conditions were provided to the test specimens: 
(1) First curing condition (CC-I): Temperature $=22^{\circ} \mathrm{C}$, Relative Humidity $=55-65 \%$

(2) Second curing condition (CC-II): Temperature $=35^{\circ} \mathrm{C}$, Relative Humidity $=35-45 \%$

(3) Third curing condition (CC-I): Temperature $=50^{\circ} \mathrm{C}$, Relative Humidity $=25-35 \%$

For maintaining the desired curing conditions, a temperature controllable cabinet was used. The required relative humidity at various temperatures was obtained by placing saturated salt solutions (sodium nitrate at $22^{\circ} \mathrm{C}$, potassium carbonate at $35^{\circ} \mathrm{C}$ and potassium chloride at $\left.50^{\circ} \mathrm{C}\right)$.

\section{Test Results and Discussion}

Setting time tests with varying admixture contents were performed under the specified curing conditions. An average of three test readings was taken as the final reading. To compare the changes occurred in setting times by incorporation of the admixture, the setting time of cement paste with out admixture content under CC-1 was used as reference. The setting times were recorded in minutes. These results are presented in the following tables and figures.

The data in Table 3 are graphically shown in Figures 1 and 2. The bestfitted curves are indicated in the Figures along with their characteristics. The series 1, 2 and 3 in Figures 1 and 2 give the variation of initial and final setting times with the admixture contents under CC-I, CC-II and CC-III, respectively.

Table 3: Setting Times of Type-A Cement Containing Varying Admixture Contents under Different Curing Conditions.

\begin{tabular}{|l|l|l|l|l|l|l|}
\hline Admixture (\%) & \multicolumn{2}{|c|}{ CC-I } & \multicolumn{2}{c|}{ CC-II } & \multicolumn{2}{c|}{ CC-III } \\
\hline & Initial & Final & Initial & Final & Initial & Final \\
\hline 0.00 & 163 & 245 & 99 & 137 & 78 & 105 \\
\hline 0.125 & 307 & 396 & 213 & 272 & 120 & 152 \\
\hline 0.25 & 619 & 741 & 272 & 332 & 226 & 300 \\
\hline 0.375 & $\cong 720$ & $\cong 820$ & 439 & 577 & 235 & 387 \\
\hline
\end{tabular}


Table 4: Relative Retarding Effect of Admixture on the Setting Times of TypeA cement Under Different Curing Conditions in Comparison with the Reference Setting Times.

\begin{tabular}{|c|r|r|l|r|l|l|}
\hline Admixture (\%) & \multicolumn{2}{|c|}{ CC-I } & \multicolumn{2}{c|}{ CC-II } & \multicolumn{2}{c|}{ CC-III } \\
\hline & Initial & Final & Initial & Final & Initial & Final \\
\hline 0.00 & 1 & 1 & 0.607 & 0.559 & 0.478 & 0.429 \\
\hline 0.125 & 1.88 & 1.616 & 1.307 & 1.110 & 0.736 & 0.620 \\
\hline 0.25 & 3.80 & 3.024 & 1.669 & 1.355 & 1.386 & 1.224 \\
\hline 0.375 & 4.42 & 3.347 & 2.693 & 2.355 & 1.442 & 1.580 \\
\hline
\end{tabular}

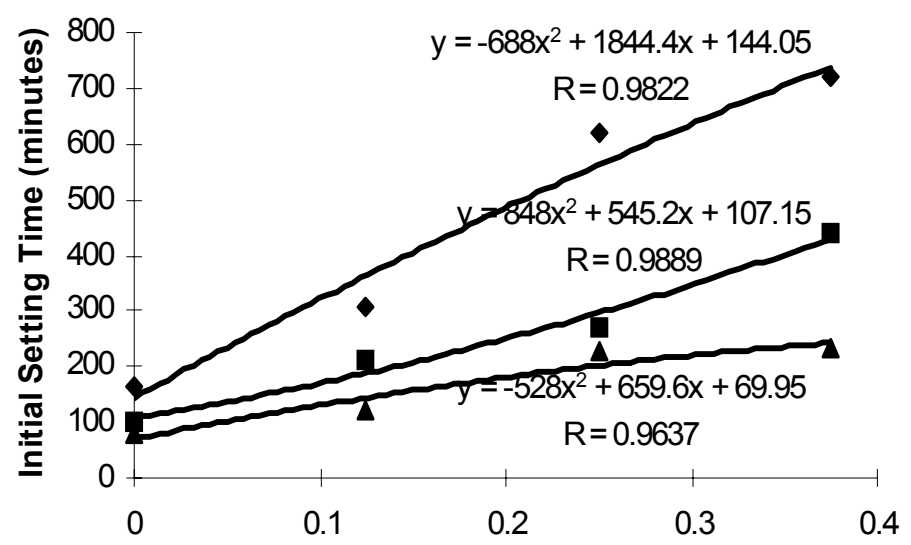

Admixture in $\mathrm{ml} / 100 \mathrm{~g}$ of Cement

Fig. 1 Effect of the Admixture on Initial Setting Time of Type-A Cement.

Table 5: Setting Times Of Type-B Cement Containing Varying Admixture Contents Under Different Curing Conditions.

\begin{tabular}{|l|l|l|l|l|l|l|}
\hline Admixture (\%) & \multicolumn{2}{|c|}{ CC-I } & \multicolumn{2}{c|}{ CC-II } & \multicolumn{2}{c|}{ CC-III } \\
\hline & Initial & Final & Initial & Final & Initial & Final \\
\hline 0.00 & 149 & 240 & 118 & 184 & 100 & 134 \\
\hline 0.125 & 215 & 358 & 127 & 232 & 108 & 155 \\
\hline 0.25 & 145 & 551 & 64 & 308 & 61 & 212 \\
\hline 0.375 & 62 & 662 & 55 & 314 & 45 & 184 \\
\hline 0.50 & 58 & 642 & - & - & - & - \\
\hline
\end{tabular}

Setting times are in minutes 


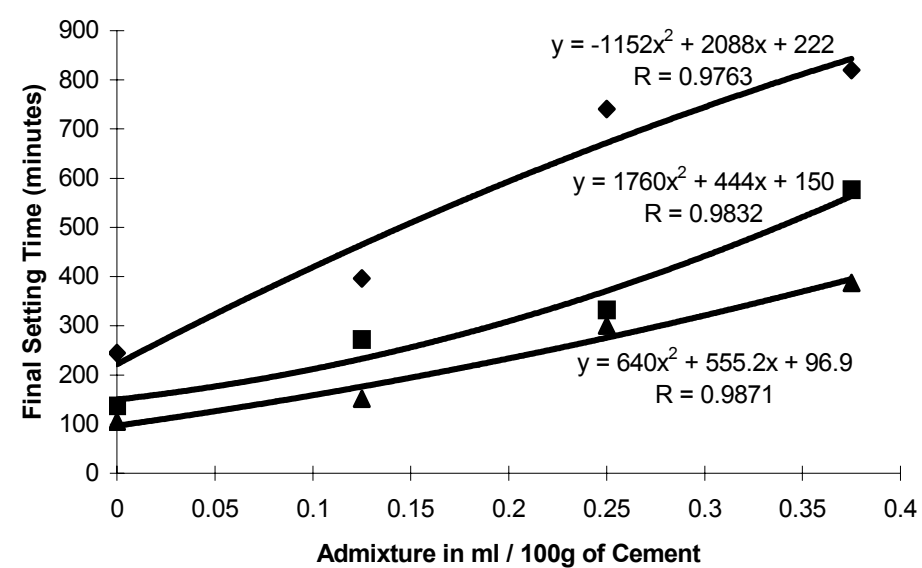

Figure 2: Effect of the Admixture on Final Setting Time of the Type-A Cement.

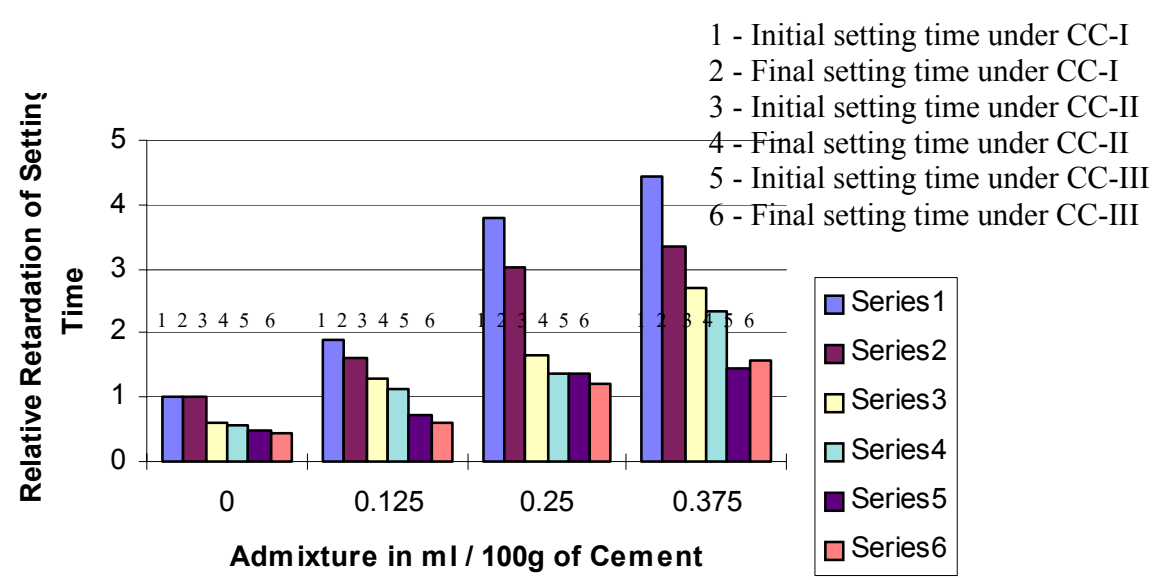

Fig. 3: Relative Retarding Effect of the Admixture on the Type-A Cement Setting

Times under Different Curing Conditions in Comparison with the Reference.

The results of Table 4 are graphically shown in Figure 3. The series 1, 3, and 5 give the relative initial setting times while the series 2, 4, and 6 give the relative final setting times under CC-I, CC-II and CC-III, respectively. 
Table 6: Relative Retarding Effect of Admixture on the Setting Times of the Type-B cement Under Different Curing Conditions in Comparison with the Reference Setting Times.

\begin{tabular}{|l|r|r|l|l|l|l|}
\hline $\begin{array}{l}\text { Admixture } \\
(\%)\end{array}$ & \multicolumn{2}{|c|}{ CC-I } & \multicolumn{2}{c|}{ CC-II } & \multicolumn{2}{c|}{ CC-III } \\
\hline & Initial & Final & Initial & Final & Initial & Final \\
\hline 0.00 & 1 & 1 & 0.792 & 0.725 & 0.671 & 0.558 \\
\hline 0.125 & 1.443 & 1.492 & 0.852 & 0.967 & 0.725 & 0.646 \\
\hline 0.25 & 0.973 & 2.296 & 0.430 & 1.283 & 0.409 & 0.883 \\
\hline 0.375 & 0.416 & 2.758 & 0.369 & 1.308 & 0.302 & 0.767 \\
\hline
\end{tabular}

The results of Table 5 are graphically shown in Figures 4 and 5 . The bestfitted curves along with their characteristics are shown. In Figure 4, the series 1, 2 and 3 show initial setting time of cement under CC-I, CC-II and CC-III, respectively, while in Figure 5 the same series show the final setting time of the cement.

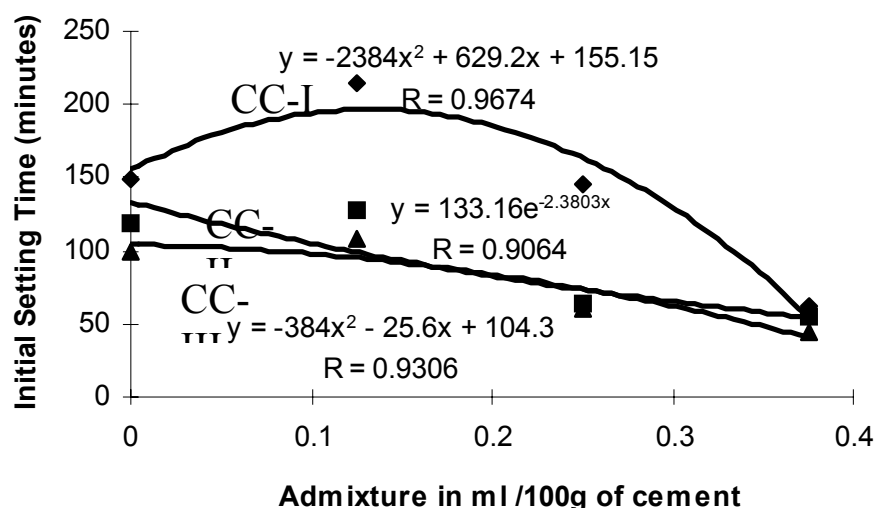

Admixture in $\mathrm{ml} / 100 \mathrm{~g}$ of cement

Fig. 4: Effect of the Admixture on Initial Setting Time of the Type-B Cement.

The results of Table 6 are graphically shown in Figure 6. The series 1, 3, and 5 give the relative initial setting times while the series 2, 4 , and 6 give the relative final setting times under CC-I, CC-II and CC-III, respectively. 


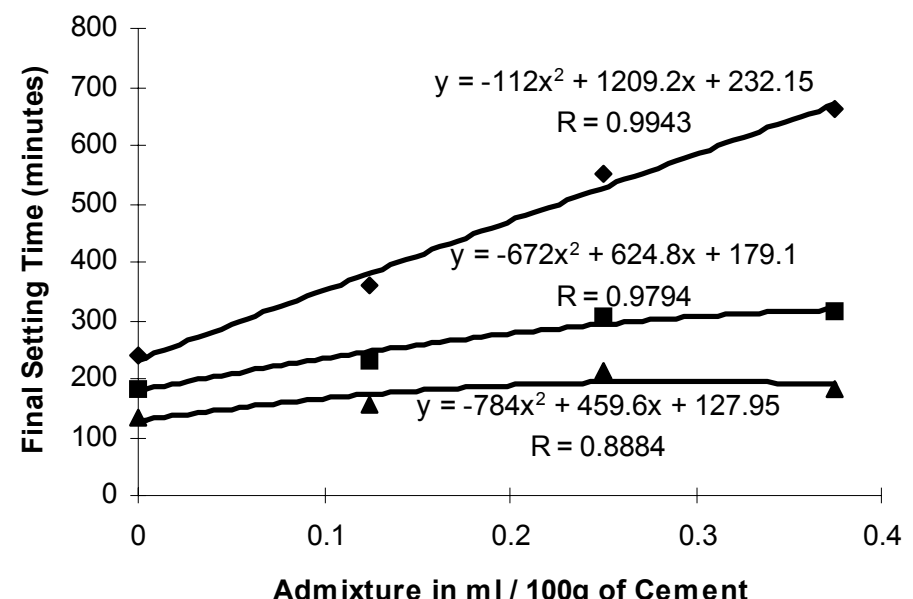

- Series 1

Fig. 5: Effect of the Admixture on Final Setting Time of the Type-B Cement

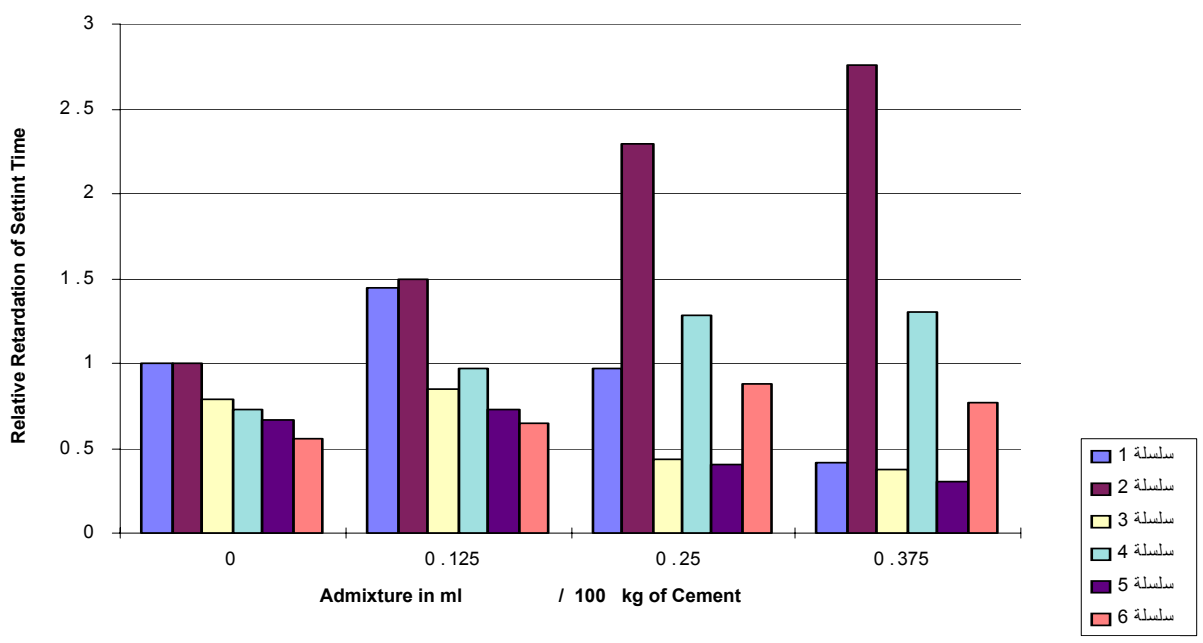

Fig. 6: Relative Retarding Effect of the Admixture on the Setting Times of the Type-B Cement under Different Curing Conditions in Comparison with the Reference Setting Times

The results of Table 7 are graphically shown in Figures 7 and 8. The bestfitted curves along with their characteristics are shown. In Figure 7 the series 1, 2 and 3 show initial setting times of cement under CC-I, CC-II and CC-III, respectively, while in Figure 8 the same series show the final setting time of the cement. 
Table 7: Setting Times of the Type-C Cement Containing Varying Admixture Content under Different Curing Conditions.

\begin{tabular}{|c|l|l|l|l|l|r|}
\hline $\begin{array}{l}\text { Admixture } \\
(\%)\end{array}$ & \multicolumn{2}{|l|}{ CC-I } & \multicolumn{2}{l|}{ CC-II } & \multicolumn{2}{l|}{ CC-III } \\
\hline & Initial & Final & Initial & Final & Initial & Final \\
\hline 0.00 & 113 & 202 & 96 & 138 & 76 & 117 \\
\hline 0.125 & 260 & 355 & 188 & 260 & 112 & 205 \\
\hline 0.25 & 456 & 700 & 300 & 405 & 125 & 296 \\
\hline 0.375 & $\cong 600$ & $\cong 708$ & 353 & 638 & 128 & 329 \\
\hline
\end{tabular}

Setting times are in minutes

Table 8: Relative Retarding Effect of Admixture on the Setting Times of the Type-C cement Under Different Curing Conditions in Comparison with the Reference Setting Times.

\begin{tabular}{|c|c|c|l|l|l|r|}
\hline $\begin{array}{l}\text { Admixture } \\
(\%)\end{array}$ & \multicolumn{2}{|l|}{ CC-I } & \multicolumn{1}{l|}{ CC-II } & \multicolumn{2}{l|}{ CC-III } \\
\hline & Initial & Final & Initial & Final & Initial & Final \\
\hline 0.00 & 1 & 1 & .85 & 0.683 & 0.673 & 0.579 \\
\hline 0.125 & 2.30 & 1.757 & 1.664 & 1.287 & 0.991 & 1.105 \\
\hline 0.25 & 4.04 & 3.465 & 2.655 & 2.005 & 1.106 & 1.465 \\
\hline 0.375 & 5.31 & 3.505 & 3.124 & 3.158 & 1.133 & 1.629 \\
\hline
\end{tabular}

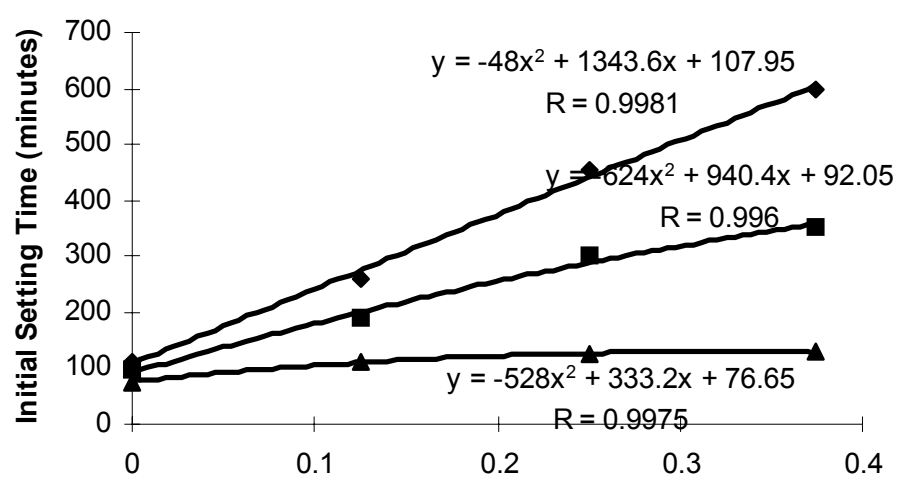

- Series 1

Series2

$\triangle$ Series3

Admixture in $\mathrm{ml} / 100 \mathrm{~g}$ of Cement

Fig. 7: Effect of the Admixture on Initial Setting Time of the Type-C Cement.

The results of Table 8 are graphically shown in Figure 9. The series 1, 3, and 5 give the relative initial setting times while the series 2,4 , and 6 give the relative final setting times under CC-I, CC-II and CC-III, respectively. 


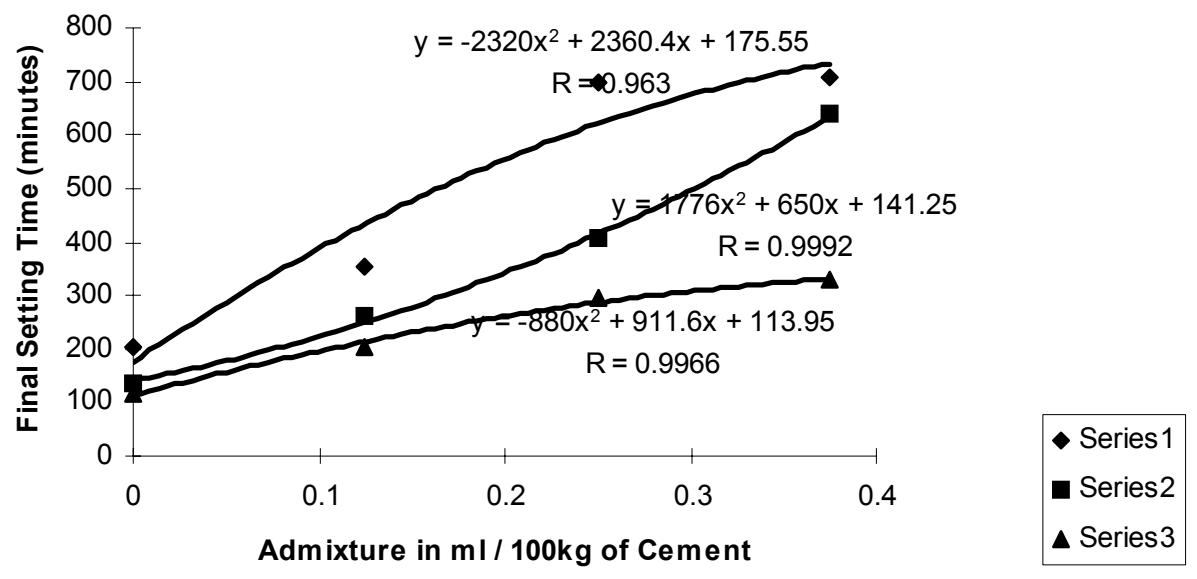

Fig. 8: Effect of the Admixture on Final Setting Time of the Type-C Cement.

The results reveal that for each of the three types of cements, high temperatures and low relative humidity reduced both the initial and final setting times. This trend is in agreement with most of the relevant published works of other researchers. Higher curing temperatures and low relative humidity accelerate the hydration of cement, consequently the necessary amount of the hydration products giving rigidity to the cement paste is formed with in shorter period. Thus, setting times are lowered.

The temperature effects on setting times in the range of $22-35^{\circ} \mathrm{C}$ are greater than in the range $35-50^{\circ} \mathrm{C}$. For example, for the type-A cement paste without admixture, the initial setting time were reduced by about $40 \%$ when comparing 35 to $22^{\circ} \mathrm{C}$ and $21 \%$ when comparing 50 to $35^{\circ} \mathrm{C}$. Similar results are also shown by other researchers [17].

The addition of the retarding admixture caused marked retardation (i.e., setting times are extended) for each of the three cements under the three curing conditions. When admixture is incorporated into cement pastes, the rate of hydration slows down. Consequently, the necessary amount of the hydration products giving rigidity to the cement paste will require longer time. Thus, cement pastes having retarding admixture remains plastic for longer time.

At a given temperature and relative humidity the retarding tendency of the admixture increased with higher admixture content as revealed by the Figs. 1, 2, $4,5,7$ and 8 . The retarding effects of a retarder when added to a mix continue until it is removed from the solution by reaction with $\mathrm{C}_{3} \mathrm{~A}$ from the cement or 
by some other way, it is removed and incorporated into the hydrated material. When higher admixture content is added to a mix, apparently more time will be needed for its removal from the solution, that is why that retardation tendency of any retarder usually increases with its higher contents.

The results also reveal that for constant admixture content, the set-retarding tendency decreased at higher temperatures and low relative humidity. In case of the type-A cement, the highest admixture content $(0.375 \%)$ caused an increase of $342 \%$ in setting times under CC-I, $169 \%$ under CC-II and $44 \%$ under CC-III. with respect to the reference setting times. Similarly for the type-C cement, the increase in setting times was $431 \%$ under CC-I, 212\% under CC-II and 135 under CC-III. Retarding admixtures causes set retardation by slowing down the rate of early hydration of $\mathrm{C}_{3} \mathrm{~S}$. At elevated temperature, the reaction between $\mathrm{C}_{3} \mathrm{~A}$ and gypsum is also activated resulting into a relatively large amount of ettringite $\left(3 \mathrm{CaO} \cdot \mathrm{Al}_{2} \mathrm{O}_{3} \cdot 3 \mathrm{CaSO}_{4} \cdot 31 \mathrm{H}_{2} \mathrm{O}\right)$ during the early stage of hydration. The lower retarding tendency of the admixture at elevated temperatures is probably due to the adsorption of the admixture on the ettringite. Consequently, lower concentration of the admixture is left to retard the $\mathrm{C}_{3} \mathrm{~S}$ hydration.

The bar charts in Figure 3 and 9 reveal that loss in setting times due to temperature of $35^{\circ} \mathrm{C}$ was completely recovered by incorporating $0.125 \%$ of the retarding admixture into the cement paste while the effects of $50^{\circ} \mathrm{C}$ temperature were completely recovered by $0.25 \%$ content of the retarding admixture.

In case of the type-B cement, the initial setting times were shortened by adding the admixture to the pastes while the final setting times were extended. This behavior of the admixture was observed under each of the three curing conditions as indicated in Figs. 4 and 5. The exact cause of this abnormal behavior of the retarding admixture to accelerate the initial set is not known. However, in the author's opinion this may be due to the addition of the greater percent of pozzolana to this cement. It is reported by some researchers that in addition to the reaction between lime and pozzolana, some other reaction between $\mathrm{C}_{3} \mathrm{~A}$ or its hydration products and pozzolana can occur [19]. There may be some reaction between the pozzolana and the admixture to form some compounds giving rigidity to the paste earlier than that obtained by the hydration products of the cement. The final setting is again obtained due to the hydration products of the cement as usual. Thus, care should be exercised while using retarding admixture with pozzolanic cements. Trial tests should be performed before use to confirm the behavior of any retarding admixture with such cements. 


\section{Conclusions}

(1) High temperature and low humidity accelerated the setting of cement pastes for all mixes with and without the retarding admixture.

(2) The retarding admixture successfully retarded cement setting under each curing condition.

(3) The retarder showed lower retarding tendency at higher temperatures and lower humidity.

(4) The loss in setting times (with respect to the reference setting times) at $35^{\circ} \mathrm{C}$ was recovered by adding $0.125 \%$ of the admixture to the mix while at $50^{\circ} \mathrm{C}$, it was recovered by adding $0.25 \%$ of the admixture.

(5) With the type-B cement, the admixture showed accelerating effects on initial set. So, caution is needed when using retarders with pozzolanic type cements.

\section{References}

[1] Baradan B. (1998). Construction Materials $-I I\left(5^{\text {th }} \cdot\right.$ ED). Dokuz Eylul University, Technical faculty publication section, Izmir Turkey.

[2] Jiang S. P., Mutin J. C. \& Nonat A. (1995). Studies on mechanism and phisco-chemical parameters at the origin of cement setting, Cement \& Concrete Research, Vol. 25,No.4, pp. $779-789$.

[3] Chen Y. \& Older I. (1992). On the origin of Portland cement setting. Cement \& Concrete Research, Vol. 22,No.6, pp. 1130 - 1140.

[4] Annual book of ASTM Standards (1979), part 13, ASTM C 191 - 77: Standard test method for time of setting of hydraulic cement. ASTM Race st. Philodelphia, pa. 19103

[5] Tanos j., Ujhelyi \& Ibrahim J. A. (1991). Hot weather concreting with hydraulic additives. Cement \& Concrete Research, Vol. 21,No.2/3, pp. 345 - 354 .

[6] Fattuhi N. I. (1988). The setting of mortar mixes subjected to different temperatures. Cement \& Concrete Research, Vol. 18,No.5, pp. $669-673$.

[7] Neville A. M. (1995). Properties of concrete ( $2^{\text {nd }}$. Ed). Longman Group Limited.

[8] Portland Cement Association (1968). Design and control of concrete mixes (11 ${ }^{\text {th }}$. Ed), 5420 old orchard road, Skokia, Illions 60076.

[9] Kjellson K. O., Wilter J. R. \& Gjørv E. V. (1990). Pore structure of plain cement pastes hydrated at different temperatures. Cement \& Concrete Research, Vol. 20,No.6, pp. 112 120.

[10] Al-Gahtani, H. J., Abbasi A. J. \& Al-Amoudi O. S. B. (1998). Concrete mixing design for hot weather: experimental and statistical analysis. Magazine of Concrete Research, Vol.50, No.2, pp. $95-105$.

[11] United States Department of Transportation - Federal Highway Administration (1999). www. Fhwa.dot.gov/engineering/hng20/hng23/setretrd.htm

[12] Annual Book of ASTM Standards (1982), part 14, concrete and mineral aggregates. C 494-81: standard specifications for chemical admixtures for concrete.

[13] Banfil, P.F.G., \& Saunders, D.C. (1986). The relationship between the sorption of organic compounds on cement and the retardation of hydration. Cement and Concrete Research, Vol.6, No.3, pp. $399-410$. 
[14] Thomas N.L. \& Brichal J.D. (1983). The retarding action of sugar on cement hydration. Cement and Concrete Research, Vol.13, No.6, pp. 830 - 842.

[15] Thomas N.L., Jameson P.A. \& Double D.D. (1981). The effect of lead nitrate on the early hydration of Portland cement. Cement and Concrete Research, Vol.11, No.1, pp. 143 - 153.

[16] Erdogan, T.Y. (1997). Admixtures for concrete, Middle East Technical University AnkaraTurkey.

[17] Alshamsi A.M., Alhosani K.I. \& Yousari K.M. (1997). Hydrophobic materials, superplasticizers and microsilica effects on setting of cement at various temperatures. Magazine of concrete research, Vol. 49, No. 179, pp. 111 - 115.

[18] Master Builder Technologies (1999). www.wiley.vch.de

[19] Plowan C \& Cabera J.G. (1984). Mechanism and kinetics of hydration of $\mathrm{C}_{3} \mathrm{~A}$ and $\mathrm{C}_{4} \mathrm{AF}$. Cement and Concrete Research, Vol. 14, No. 2, pp.238 - 248. 
أثر مخلوط مادة مؤخرة على مدة تشبت معلجين الإيسمنت في الجو الحار

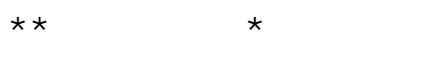

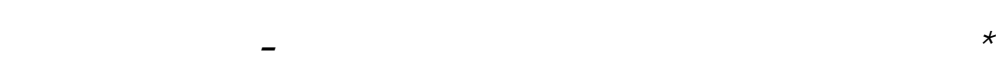

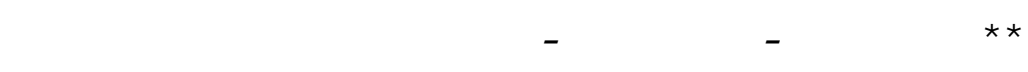

المستخلص: أثناء لمتنعمل الخرسانة في الجو الحار، ينأثر كل

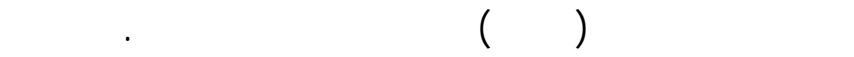

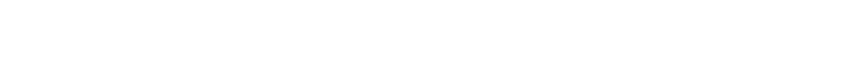

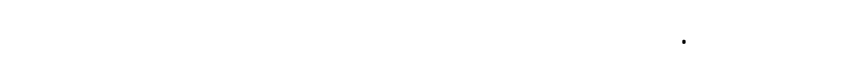

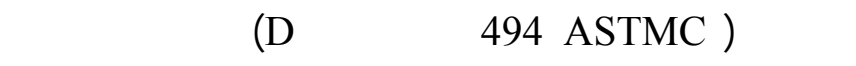

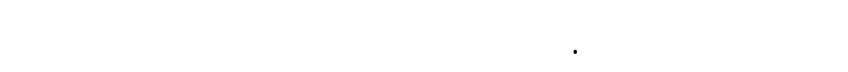
ثلاث حالات مختلفة ( درجة الحرارة والرطوبة النسبية) .

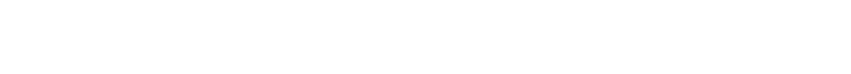

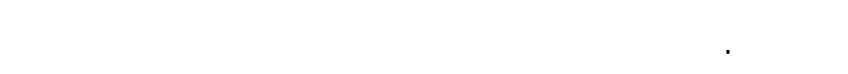

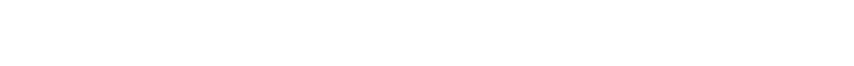

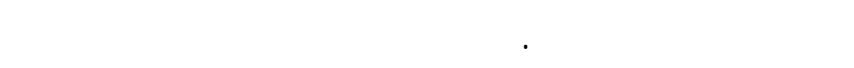

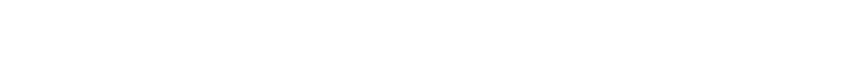

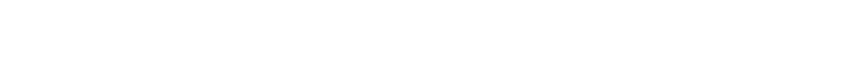

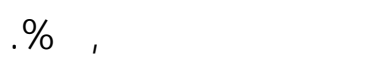

